\title{
Solvent Effects on the Energetics of the Phenol O-H Bond: Differential Solvation of Phenol and Phenoxy Radical in Benzene and Acetonitrile
}

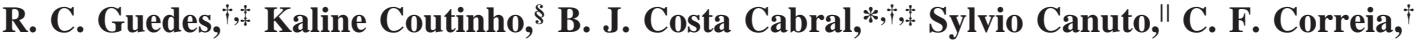 \\ R. M. Borges dos Santos, ${ }^{\#}$ and J. A. Martinho Simões ${ }^{\dagger}$ \\ Departamento de Química e Bioquímica, Faculdade de Ciências da Universidade de Lisboa, \\ 1749-016 Lisboa, Portugal, Grupo de Física Matemática da Universidade de Lisboa, Av. Professor Gama \\ Pinto 2, 1649-003 Lisboa, Portugal, Universidade de Mogi das Cruzes, CP 411, 08701-970 Mogi das Cruzes, \\ São Paulo, Brazil, Instituto de Física, Universidade de São Paulo, CP 66318, 05315-970 São Paulo, \\ São Paulo, Brazil, and Faculdade de Engenharia de Recursos Naturais, Universidade do Algarve, \\ Campus de Gambelas, 8005-139 Faro, Portugal
}

Received: July 3, 2003; In Final Form: September 4, 2003

\begin{abstract}
Monte Carlo statistical mechanics simulations, density-functional theory calculations, time-resolved photoacoustic calorimetry, and isoperibol reaction-solution calorimetry experiments were carried out to investigate the solvation enthalpies and solvent effects on the energetics of the phenol $\mathrm{O}-\mathrm{H}$ bond in benzene and acetonitrile. A good agreement between theoretical and experimental results is obtained for the solvation enthalpies of phenol in benzene and acetonitrile. The theoretical calculations also indicate that the differences between the solvation enthalpies of phenol $(\mathrm{PhOH})$ and phenoxy radical $\left.(\mathrm{PhO})^{\circ}\right)$ in both benzene and acetonitrile are significantly smaller than previous estimations based on the ECW model. The results for the solvation enthalpies are used to obtain the $\mathrm{O}-\mathrm{H}$ bond dissociation enthalpies in benzene and acetonitrile. For benzene and acetonitrile, the theoretical results of $89.4 \pm 1.2$ and $90.5 \pm 1.7 \mathrm{kcal} \mathrm{mol}^{-1}$, respectively, are in good agreement with the experimental values $\left(90.9 \pm 1.3\right.$ and $\left.92.9 \pm 0.9 \mathrm{kcal} \mathrm{mol}^{-1}\right)$, obtained by photoacoustic calorimetry. The solute-solvent interaction energies of phenol and phenoxy radical with both acetonitrile and benzene differ by less than $2 \mathrm{kcal} \mathrm{mol}^{-1}$. A detailed analysis of the solvent contributions to the differential solvation enthalpy is made in terms of the hydrogen bonds and the solute-solvent interactions. $\mathrm{Both} \mathrm{PhOH}$ and $\mathrm{PhO}^{\bullet}$ induce a significant, although equivalent, solvent reorganization enthalpy. Finally, the convergence of the solute-solvent interaction is analyzed as a function of the distance to the solute and illustrates the advantages and limitations of local models such as microsolvation and hydrogen-bond-only models.
\end{abstract}

\section{Introduction}

The homolytic dissociation of the $\mathrm{O}-\mathrm{H}$ bond in phenol leads to the formation of the phenoxy radical $\left(\mathrm{PhO}^{\circ}\right)$, which is an important intermediate in the combustion of many aromatic compounds, ${ }^{1-4}$ green plant photosynthesis, ${ }^{5}$ biocatalysis,${ }^{6}$ and protein redox reactions. ${ }^{7}$ The energetics of the $\mathrm{PhO}-\mathrm{H}$ bond in solution and in the gas phase is a central piece of information, important to understand the mechanisms of those processes. The gas-phase bond dissociation enthalpy of phenol, $\mathrm{DH}^{\circ}(\mathrm{PhO}-$ $\mathrm{H})$, has been determined by several experimental ${ }^{8}$ and computational methods, ${ }^{9}$ the recommended value being $88.7 \pm 0.5$ $\mathrm{kcal} \mathrm{mol}^{-1}\left(371.3 \pm 2.3 \mathrm{~kJ} \mathrm{~mol}^{-1}\right) .{ }^{8}$ On the other hand, the energetics of the corresponding homolytic cleavage in solution, $D H_{\text {sln }}^{\circ}(\mathrm{PhO}-\mathrm{H})$, has also been probed through several experimental techniques, ${ }^{8,10}$ and the values are always higher than the gas-phase result. Scheme 1 or eq 1 shows the relevant quantities to consider when one wishes to relate those two sets of data.

\footnotetext{
Faculdade de Ciências da Universidade de Lisboa.

$\doteqdot$ Grupo de Física Matemática da Universidade de Lisboa.

$\S$ Universidade de Mogi das Cruzes.

" Universidade de São Paulo.

\# Universidade do Algarve.
}

$$
\begin{array}{r}
D H^{\circ}(\mathrm{PhO}-\mathrm{H})=D H_{\mathrm{sln}}^{\circ}(\mathrm{PhO}-\mathrm{H})+\Delta_{\mathrm{sln}} H^{\circ}(\mathrm{PhOH}, \mathrm{g})- \\
\Delta_{\mathrm{sln}} H^{\circ}\left(\mathrm{PhO}^{\circ}, \mathrm{g}\right)-\Delta_{\mathrm{sln}} H^{\circ}\left(\mathrm{H}^{\circ}, \mathrm{g}\right)
\end{array}
$$

The main difficulties of applying eq 1 are related to the lack of data for the solvation enthalpies of the phenoxy radical and the hydrogen atom. A way to avoid the first of these problems was suggested by Wayner et al: ${ }^{11}$ because we are dealing with the difference $\Delta_{\mathrm{sln}} H^{\circ}(\mathrm{PhOH}, \mathrm{g})-\Delta_{\mathrm{sln}} H^{\circ}\left(\mathrm{PhO}^{\circ}, \mathrm{g}\right)$, it seems reasonable to assume that this is simply given by the enthalpy of the hydrogen bond between the phenolic compound and the solvent (S). Although there are several experimental studies in which the energetics of $\mathrm{PhOH} \cdots \mathrm{S}$ intermolecular bonds were determined, ${ }^{12}$ we have found that the so-called ECW method, developed by Drago and co-workers,${ }^{13}$ provides an alternative

\section{SCHEME 1}

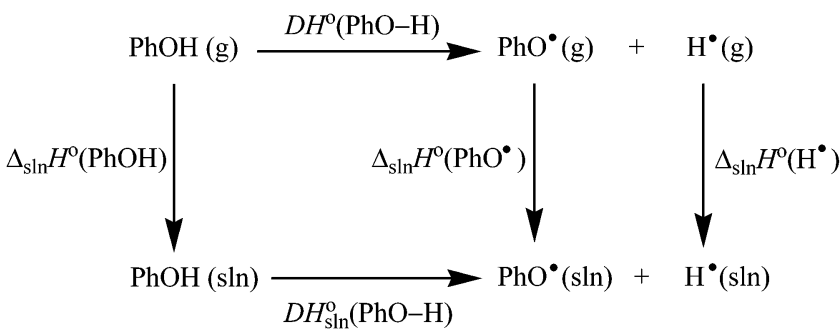

10.1021/jp035912c CCC: $\$ 25.00$ (C) 2003 American Chemical Society Published on Web 10/08/2003 
and direct way of estimating that bond enthalpy in many solvents. ${ }^{8,14,15}$ Regarding the enthalpy of solvation of the hydrogen atom, it is usually identified with the enthalpy of solvation of $\mathrm{H}_{2}$, which is nearly constant for organic solvents $\left(1.2 \pm 0.2 \mathrm{kcal} \mathrm{mol}^{-1}\right) .{ }^{8}$ However, it is important to stress that this value becomes redundant when the $\mathrm{PhO}-\mathrm{H}$ gas-phase bond dissociation enthalpy relies on $\mathrm{DH}_{\mathrm{sln}}^{\circ}(\mathrm{PhO}-\mathrm{H})$ obtained from photoacoustic calorimetry (PAC) experiments. Although this methodology is explained in detail elsewhere, ${ }^{10,15}$ it is easy to justify: the PAC-derived value for $D H_{\sin }^{\circ}(\mathrm{PhO}-\mathrm{H})$ depends on the assumption accepted for the solvation enthalpy of the hydrogen atom, and when eq 1 is applied to evaluate $D H^{\circ}$ $(\mathrm{PhO}-\mathrm{H}), \Delta_{\mathrm{sln}} H^{\circ}\left(\mathrm{H}^{\bullet}, \mathrm{g}\right)$ cancels out. In other words, $\mathrm{DH}^{\circ}(\mathrm{PhO}-$ $\mathrm{H})$ will depend only on the differential solvation enthalpy $\Delta_{\text {sln }} H^{\circ}(\mathrm{PhOH}, \mathrm{g})-\Delta_{\text {sln }} H^{\circ}\left(\mathrm{PhO}^{\circ}, \mathrm{g}\right)$.

From a theoretical perspective, the modeling of solvation of free radicals is difficult because the interactions between radical species and solvent molecules are not well-known. ${ }^{16}$ Usually, two different theoretical approaches have been adopted to study the solvation of radical species. The first one is based on "microsolvation" in small clusters, $,{ }^{9}, 17-22$ and it has been applied to a variety of free radical systems. The second approach is based on statistical mechanics simulations and has recently been applied to study the differential hydration of phenol and phenoxy radical. $^{23}$

In the present work, we report theoretical and experimental results for the solvation of phenol and phenoxy radical in benzene and acetonitrile. Our main purpose was to obtain the solvation enthalpy of these species in nonpolar (benzene) and strongly polar (acetonitrile) liquids and to use these results, together with data obtained by photoacoustic calorimetry, to derive the $\mathrm{PhO}-\mathrm{H}$ bond dissociation enthalpy in solution from the gas-phase value or vice versa. Initially, we performed density-functional theory (DFT) calculation for the energetics, structure, and electronic properties of microclusters of phenol and phenoxy radical with one and two solvent molecules. We found that this approach is also useful to understand and parametrize the interactions between the solvated species and the solvents. Statistical mechanics Monte Carlo (MC) simulations were then carried out to analyze the structure and thermodynamics of the solutions and the relationship between the solvation enthalpies of phenol and phenoxy radical, which were then used to bridge the energetics of the phenol $\mathrm{O}-\mathrm{H}$ bond in solution and in the gas phase. Thermodynamic perturbation theory ${ }^{24-27}$ calculations were also carried out to evaluate the difference between the solvation Gibbs energies of phenol and phenoxy radical in benzene and acetonitrile.

\section{Procedures}

Density-Functional Theory Calculations. The structures of phenol and phenoxy radical clusters with one and two molecules of benzene and acetonitrile were fully optimized by DFT calculations. These calculations were based on the Becke's threeparameter B $3^{28}$ with the Lee, Yang, and Parr (LYP) ${ }^{29}$ correlation functional. Full geometry optimizations were carried out with the $6-31 G(d, p)$ basis set. ${ }^{30}$ Single-point energy calculations with the $6-31+\mathrm{G}(\mathrm{d}, \mathrm{p})^{30}$ and $6-311++\mathrm{G}(\mathrm{d}, \mathrm{p})$ basis set ${ }^{31}$ are also reported. Binding energies of the clusters were corrected for basis set superposition error (BSSE) by using the counterpoise method $^{32}$ including the fragment relaxation contributions. ${ }^{33}$ The DFT calculations were carried out with the Gaussian 98 program. ${ }^{34}$ The optimized structures are shown in Figure 1
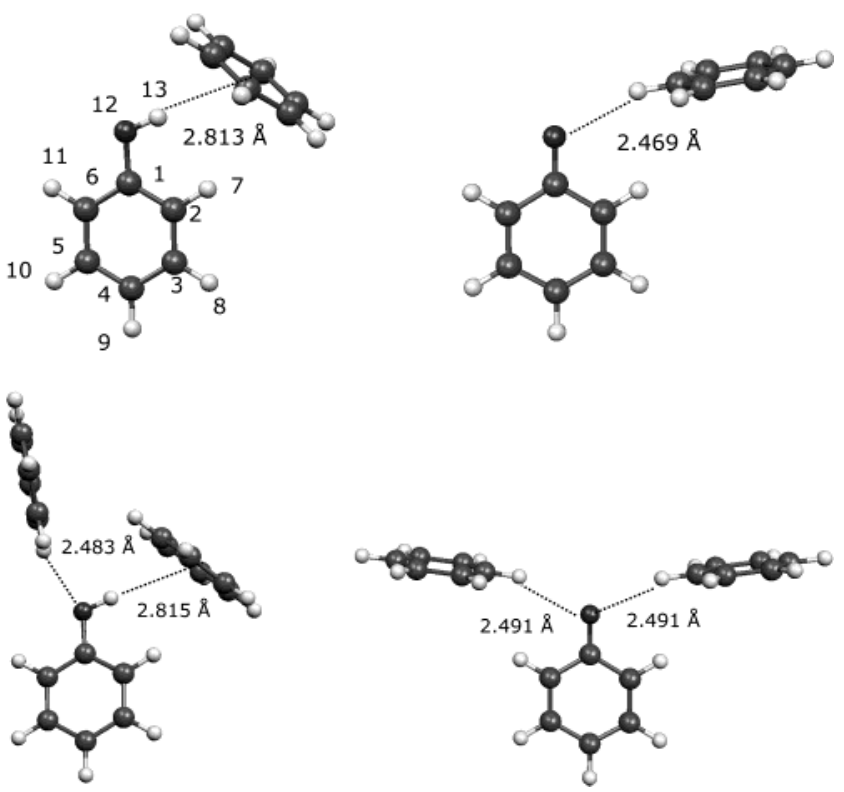

Figure 1. Optimized structures (B3LYP/6-31G(d,p)) for clusters of phenol (left) and phenoxy radical (right) with one and two benzene molecules.
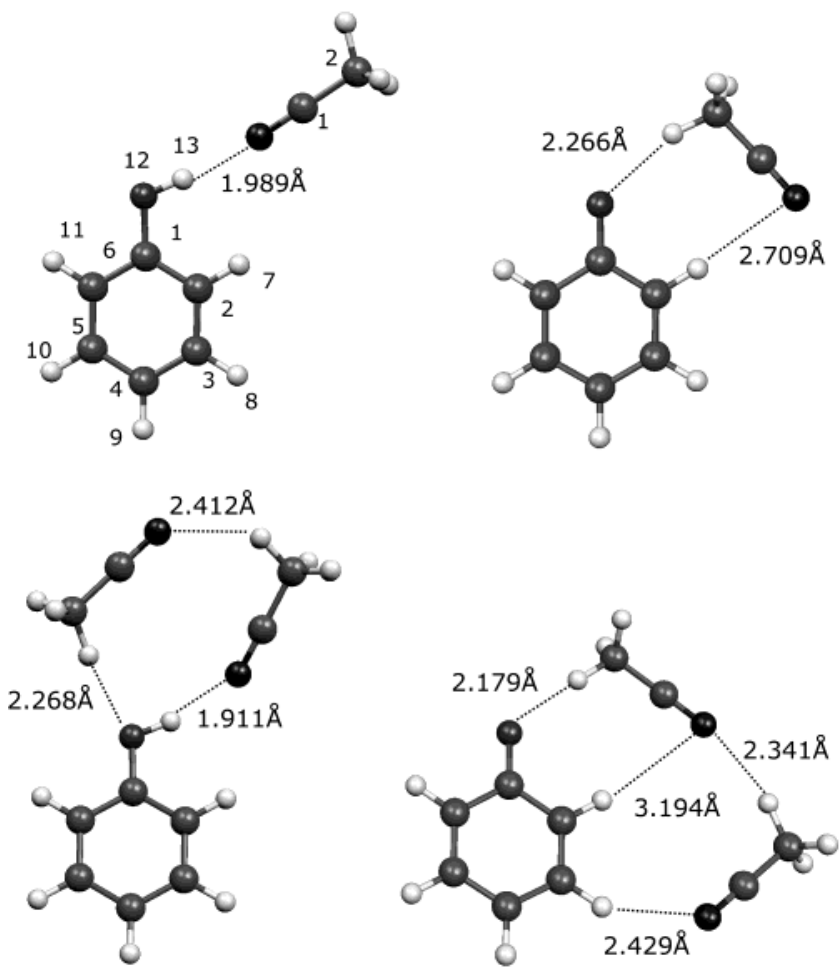

Figure 2. Optimized structures (B3LYP/6-31G(d,p)) for clusters of phenol (left) and phenoxy radical (right) with one and two acetonitrile molecules.

(phenol and phenoxy radical with benzene) and Figure 2 (phenol and phenoxy radical with acetonitrile). The results of these calculations were used to parametrize the atomic charges for the MC simulations and to discuss the microcluster (or microsolvation) model applied to phenol and phenoxy in benzene and acetonitrile.

Monte Carlo Simulations. Monte Carlo simulations of phenol and phenoxy radical in benzene and acetonitrile were carried out in the isobaric-isothermal $(N p T)$ ensemble $^{35}$ at $T$ $=25^{\circ} \mathrm{C}$ and $p=1 \mathrm{~atm}$. The interactions between two molecules $a$ and $b$ were described by a Lennard-Jones plus a Coulomb 
contribution, with parameters $\epsilon_{i}, \sigma_{i}$, and $q_{i}$ for each atom:

$$
U_{a b}=\sum_{i \in a} \sum_{j \in b} 4 \epsilon_{i j}\left[\left(\frac{\sigma_{i j}}{r_{i j}}\right)^{12}-\left(\frac{\sigma_{i j}}{r_{i j}}\right)^{6}\right]+\frac{q_{i} q_{j} e^{2}}{r_{i j}}
$$

The Lennard-Jones parameters for the phenol molecule and phenoxy radical are those proposed by Jorgensen and Nguyen for pure liquid phenol. ${ }^{36}$ For the benzene molecules, the geometry and interaction parameters for the twelve-site model are those proposed by Jorgensen and Severance. ${ }^{37}$ This model describes quite well the properties of pure liquid benzene. For acetonitrile, we have adopted the six-site model proposed by Böhm et al. ${ }^{38}$ In all simulations, the molecules have a rigid geometry. Long-range corrections to the Lennard-Jones interactions were included. The geometry of phenol (planar form) and phenoxy radical were obtained from DFT optimizations. The internal rotation of the phenol $\mathrm{O}-\mathrm{H}$ group, which is related to an energy barrier of $2.55 \mathrm{kcal} \mathrm{mol}^{-1}, 39$ was not included.

The Coulombic interactions between the solutes (phenol or phenoxy) and the solvents (benzene or acetonitrile) were derived by fitting the charges of the solute to the electrostatic potential $^{40,41}$ in small clusters with two solvent molecules (see Figures 1 and 2). The fit used the Merz-Kollman procedure. ${ }^{40,41}$ The calculation of the solute charges in the clusters takes into account, at least partially, the polarization of the solute by the solvent charges. With the use of this method, the phenoxy radical charge distribution is slightly asymmetric, but we have verified that it leads to essentially equivalent solute-solvent interactions if a symmetrized charge distribution is used. The charges were calculated at the B3LYP/6-311++G(d,p) level with B3LYP/ 6-31G(d,p) optimized geometries. We have not taken into account how polarization effects induced by the solutes may influence the solvent charge distribution. The solvents are being represented by nonpolarizable interaction models. However, we believe that polarization induced by the solutes will affect mainly the solvent molecules in the first coordination shell. Moreover, they will possibly cancel out when we consider the differential solvation of phenol and phenoxy radical, because it can be expected that they are similar for both species.

The interaction parameters are reported in Table 1, together with the gas-phase dipole moments $\left(\mu_{\mathrm{g}}\right)$ of phenol and phenoxy radical and the dipole moments in the clusters with two solvent molecules $\left(\mu_{\mathrm{cl}}\right)$. We note that $\mu_{\mathrm{g}}$ for the phenoxy radical (4.07 D) is significantly larger than the gas-phase dipole of phenol (1.39 D), which is in very good agreement with experiment (1.4 D). ${ }^{42}$ We find very small variations of the phenol and phenoxy radical dipole moments in the clusters with two benzene molecules relative to the isolated species. For example, the dipole moment of phenol in the cluster with two benzene molecules is $1.60 \mathrm{D}$, only $0.2 \mathrm{D}$ larger than the gas-phase result. Our results also show that the dipole moment of the phenoxy radical in the acetonitrile cluster $\left(\mu_{\mathrm{cl}}=5.02 \mathrm{D}\right)$ is significantly increased by comparison with the gas-phase value $\left(\mu_{\mathrm{g}}=4.07\right.$ D). We also note a significant increase of the phenol dipole moment from $\mu_{\mathrm{g}}=1.39 \mathrm{D}$ to $\mu_{\mathrm{cl}}=1.97 \mathrm{D}$. The latter value is close to the liquid-phase effective dipole moment of phenol $\left(\mu_{1}\right.$ $=2.11 \mathrm{D}$ ) proposed by Jorgensen and Nguyen. ${ }^{36}$

A cubic cell with periodic boundary conditions was used in the simulations. The simulated solutions included one solute molecule (phenol or phenoxy radical) and 216 benzene or 500 acetonitrile molecules $\left(N_{\mathrm{S}}\right)$. The interactions were truncated at a cutoff distance $R_{\mathrm{c}}$. The initial configuration was generated randomly. The maximum displacement of the molecules was self-adjusted to give an acceptance ratio around 50\%. The
TABLE 1: Lennard-Jones Parameters and Charge Distribution of Phenol and Phenoxy Radical for the Interactions with Benzene and Acetonitrile and Interaction Parameters for the Solvents

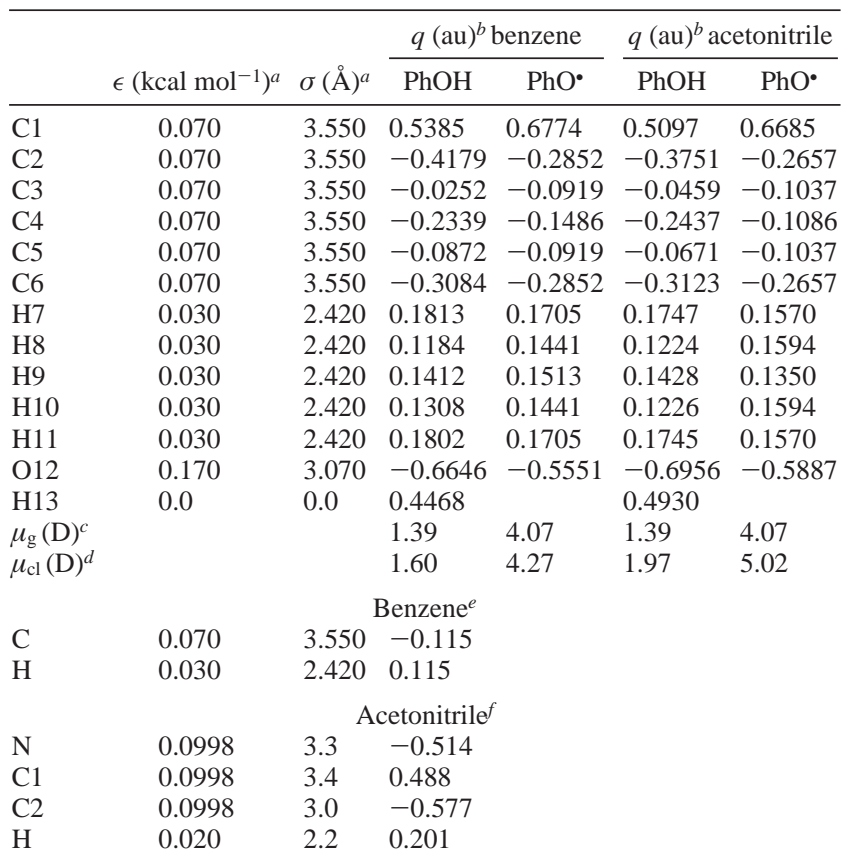

${ }^{a}$ Lennard-Jones parameters from ref 36. ${ }^{b}$ Atomic charges are MerzKollman charges from B3LYP/6-311++G(d,p) calculations. ${ }^{c} \mu_{\mathrm{g}}$ is the gas-phase dipole moment. ${ }^{d} \mu_{\mathrm{cl}}$ is the dipole moment in the cluster (see Figures 1 and 2) with two solvent molecules. ${ }^{e}$ Parameters for benzene from ref 37. ${ }^{f}$ Parameters for acetonitrile from ref 38.

volume has been perturbed once every five complete loops over all molecules in the cubic cell. Each step involved the attempt to move one molecule of the system. At least $10^{8}$ steps were carried out for equilibration. Average values were calculated over $8.6 \times 10^{8}$ (benzene) or $10.0 \times 10^{8}$ (acetonitrile) additional steps. Long simulations are needed for reliable estimation of the solvent relaxation energies. As we shall see later, the relaxation energy and the solvation enthalpies obtained here are statistically converged. The Monte Carlo simulations were performed with the DICE program. ${ }^{43}$

Photoacoustic Calorimetry. The photoacoustic calorimetry (PAC) setup and the experimental technique used to determine the $\mathrm{PhO}-\mathrm{H}$ bond dissociation enthalpies in benzene and acetonitrile were described in detail elsewhere. ${ }^{10,15,44} \mathrm{We}$ have used the time-resolved version of the technique (TR-PAC) in the experiments with both solvents. The phenol concentrations were $1.5 \times 10^{-3}$ and $0.1 \mathrm{M}$ in benzene and in acetonitrile, respectively (the higher concentration used in acetonitrile is due to a slower kinetics in this solvent due to hydrogen bonding). The results refer to $298 \mathrm{~K}$ and represent the average of five independent experiments. The assigned uncertainties are twice the standard deviation of the mean in each case.

Reaction-Solution Calorimetry. The enthalpies of solution of phenol in benzene and in acetonitrile were determined with an isoperibol reaction-solution calorimeter. ${ }^{45}$ Solute concentrations varied between $1 \times 10^{-2}$ and $2 \times 10^{-2} \mathrm{M}$. The results refer also to $298 \mathrm{~K}$ and represent the average of four (acetonitrile) or five (benzene) independent experiments. The uncertainties are twice the standard deviation of the mean in each case.

Materials. Phenol (Aldrich, 99+\%) was sublimed in a vacuum and kept under nitrogen prior to use. Acetonitrile and benzene (Aldrich) were of HPLC grade and used as received. 
TABLE 2: Binding Energies ( $\Delta E$ in $\mathrm{kcal} \mathrm{mol}^{-1}$ ) for Clusters of Phenol and Phenoxy Radical with Benzene and Acetonitrile ${ }^{a}$

\begin{tabular}{|c|c|c|c|c|}
\hline & $\mathrm{PhOH}-\left(\mathrm{C}_{6} \mathrm{H}_{6}\right)_{1}$ & $\mathrm{PhOH}-\left(\mathrm{C}_{6} \mathrm{H}_{6}\right)_{2}$ & $\mathrm{PhO}^{\bullet}-\left(\mathrm{C}_{6} \mathrm{H}_{6}\right)_{1}$ & $\mathrm{PhO}^{\bullet}-\left(\mathrm{C}_{6} \mathrm{H}_{6}\right)_{2}$ \\
\hline & & B3LYP/6-31G(d,p) & & \\
\hline$\Delta E$ & 3.07 & 4.52 & 2.11 & 3.62 \\
\hline$\Delta E(\mathrm{BSSE})$ & 1.88 & 2.22 & 0.41 & 0.27 \\
\hline $\begin{array}{l}\Delta E \\
\Delta E(\mathrm{BSSE})\end{array}$ & $\begin{array}{l}2.13 \\
1.55\end{array}$ & $\begin{array}{c}\text { B3LYP/6-31+G(d,p) } \\
2.85 \\
2.00\end{array}$ & $\begin{array}{l}0.76 \\
0.45\end{array}$ & $\begin{array}{l}1.46 \\
0.85\end{array}$ \\
\hline $\begin{array}{l}\Delta E \\
\Delta E(\mathrm{BSSE})\end{array}$ & $\begin{array}{l}2.08 \\
1.46\end{array}$ & $\begin{array}{c}\text { B3LYP/6-311++G(d,p) } \\
2.79 \\
1.91\end{array}$ & $\begin{array}{l}0.74 \\
0.46\end{array}$ & $\begin{array}{l}1.49 \\
0.91\end{array}$ \\
\hline$\Delta E(\mathrm{BSSE})$ & $\mathrm{PhOH}-\left(\mathrm{CH}_{3} \mathrm{CN}\right)_{1}$ & $\mathrm{PhOH}-\left(\mathrm{CH}_{3} \mathrm{CN}\right)_{2}$ & $\mathrm{PhO} \cdot-\left(\mathrm{CH}_{3} \mathrm{CN}\right)_{1}$ & $\mathrm{PhO} \cdot-\left(\mathrm{CH}_{3} \mathrm{CN}\right)_{2}$ \\
\hline $\begin{array}{l}\Delta E \\
\Delta E(\mathrm{BSSE})\end{array}$ & $\begin{array}{l}6.39 \\
5.11\end{array}$ & $\begin{array}{c}\text { B3LYP/6-31G(d,p) } \\
9.03 \\
6.62\end{array}$ & $\begin{array}{l}4.69 \\
2.92\end{array}$ & $\begin{array}{l}5.82 \\
3.38\end{array}$ \\
\hline $\begin{array}{l}\Delta E \\
\Delta E(\mathrm{BSSE})\end{array}$ & $\begin{array}{l}5.41 \\
5.01\end{array}$ & $\begin{array}{c}\text { B3LYP/6-31+G(d,p) } \\
7.27 \\
6.63\end{array}$ & $\begin{array}{l}3.22 \\
3.03\end{array}$ & $\begin{array}{l}4.31 \\
3.98\end{array}$ \\
\hline $\begin{array}{l}\Delta E \\
\Delta E(\mathrm{BSSE})\end{array}$ & $\begin{array}{l}5.46 \\
5.12\end{array}$ & $\begin{array}{c}\text { B3LYP/6-311++G(d,p) } \\
7.32 \\
6.75\end{array}$ & $\begin{array}{l}3.22 \\
3.03\end{array}$ & $\begin{array}{l}4.35 \\
4.02\end{array}$ \\
\hline
\end{tabular}

${ }^{a}$ Binding energies include ZPVE calculated at the B3LYP/6-31G(d,p) level. $\Delta E(\mathrm{BSSE})$ are binding energies corrected for BSSE.

Di-tert-butylperoxide (Aldrich), used to produce the tert-butoxy radicals, which abstracted the hydrogen atom from $\mathrm{PhOH}$, was purified according to a literature procedure. ${ }^{46} o$-Hydroxybenzophenone (Aldrich), used to calibrate the PAC setup, was recrystalized twice from an ethanol-water mixture.

\section{Results and Discussion}

Energetics of Solvation: Microsolvation Results. The optimized structures for clusters of phenol and phenoxy radical with one and two benzene molecules are presented in Figure 1, and the corresponding binding energies are reported in Table 2. The $\mathrm{PhOH}-\left(\mathrm{C}_{6} \mathrm{H}_{6}\right)_{1}$ cluster is stabilized dominantly by the interaction of the phenol $\mathrm{O}-\mathrm{H}$ dipole with the benzene ring. The distance between the hydroxylic hydrogen and the center of the benzene ring (Figure 1a) is $2.81 \AA$ A. The binding energies obtained at B3LYP/6-311++G(d,p) level are $2.08 \mathrm{kcal} \mathrm{mol}^{-1}$ ( $\Delta E$, uncorrected for BSSE) and $1.46 \mathrm{kcal} \mathrm{mol}^{-1}(\Delta E(\mathrm{BSSE})$, after correction to BSSE). The structure of the $\mathrm{PhOH}-\left(\mathrm{C}_{6} \mathrm{H}_{6}\right)_{2}$ cluster indicates that it is further stabilized by a hydrogen bonding of $2.48 \AA$ (see Figure $1 \mathrm{~b}$ ). The $\Delta E(\mathrm{BSSE})$ is $1.91 \mathrm{kcal}$ $\mathrm{mol}^{-1}$ at the B3LYP/6-311++G(d,p) level. This binding energy reported for the $\mathrm{PhOH}-\left(\mathrm{C}_{6} \mathrm{H}_{6}\right)_{2}$ cluster is referred to its dissociation into $\mathrm{PhOH}$ and two benzene molecules in the optimized structure of the dimer $\left(\mathrm{C}_{6} \mathrm{H}_{6}\right)_{2}$.

The structures of phenoxy radical-benzene clusters indicate that these clusters are stabilized by the interactions between the phenoxy radical $\mathrm{C}-\mathrm{O}$ dipole and the quadrupole moment of the benzene. $\mathrm{O}-\mathrm{H}$ distances are $\sim 2.49 \AA . \Delta E(\mathrm{BSSE})$ is 0.46 $\mathrm{kcal} \mathrm{mol}^{-1}$ for $\mathrm{PhO}-\left(\mathrm{C}_{6} \mathrm{H}_{6}\right)_{1}$ and $0.91 \mathrm{kcal} \mathrm{mol}^{-1}$ for $\mathrm{PhO} \bullet-$ $\left(\mathrm{C}_{6} \mathrm{H}_{6}\right)_{2}$ at the B3LYP/6-311++G(d,p) level.

The corresponding optimized structures for the clusters of phenol and phenoxy radical with one and two acetonitrile molecules are shown in Figure 2. Binding energies, obtained with a similar procedure as in the case of benzene, are also reported in Table 2. The $\mathrm{PhOH}-\left(\mathrm{CH}_{3} \mathrm{CN}\right)_{1}$ cluster (Figure 2a) shows a $\mathrm{N} \cdot \cdot \mathrm{H}$ distance of $1.99 \AA$, which is related to the headto-tail interaction between the $\mathrm{O}-\mathrm{H}$ dipole of phenol and the dipole along the acetonitrile $C_{3 v}$ axis. The $\Delta E(\mathrm{BSSE})$ binding energy of this structure is $5.12 \mathrm{kcal} \mathrm{mol}^{-1}$ (B3LYP/6-311++G$(\mathrm{d}, \mathrm{p}))$, which is in excellent agreement with the value of 5.3 kcal mol ${ }^{-1}$ reported by Kryachko and Nguyen. ${ }^{47}$ The $\mathrm{PhOH}-$
$\left(\mathrm{CH}_{3} \mathrm{CN}\right)_{2}$ cluster (Figure $2 \mathrm{~b}$ ) is additionally stabilized by the antiparallel dipolar interactions between the acetonitrile molecules, which also determine the structure of the acetonitrile dimer. As in the case of benzene, the binding energy for $\mathrm{PhOH}-$ $\left(\mathrm{CH}_{3} \mathrm{CN}\right)_{2}$ cluster refers to its dissociation into $\mathrm{PhOH}$ and the acetonitrile dimer $\left(\mathrm{CH}_{3} \mathrm{CN}\right)_{2}$, optimized separately. At the $\mathrm{B} 3 \mathrm{LYP} / 6-311++\mathrm{G}(\mathrm{d}, \mathrm{p})$ level, $\Delta E(\mathrm{BSSE})$ is $6.75 \mathrm{kcal} \mathrm{mol}^{-1}$.

The structures of phenoxy radical with one and two acetonitrile molecules are apparently stabilized by $\mathrm{O} \cdots \mathrm{H}$ and $\mathrm{N} \cdots \mathrm{H}$ hydrogen bonding. Binding energies are now 3.03 and $4.02 \mathrm{kcal}$ $\mathrm{mol}^{-1}$ for phenoxy radical with one and two acetonitrile molecules, respectively.

In summary, with the largest basis set, B3LYP/6-311++G(d,p), the DFT results for the microclusters indicate that the differences between phenol and phenoxy radical interactions with the nearest solvent molecule are ca. $-1.0 \mathrm{kcal} \mathrm{mol}^{-1}$ for benzene and ca. $-2.0 \mathrm{kcal} \mathrm{mol}^{-1}$ for acetonitrile.

Energetics of Solvation: Monte Carlo Results. $H_{\mathrm{SX}}$ and $H_{\mathrm{SS}}^{*}$ represent, respectively, the total enthalpies of the solution (per solute molecule) and the pure liquid for systems with $N_{\mathrm{S}}$ solvent molecules. They are defined by eqs 3 and 4 , where $E_{\mathrm{SX}}$ is the solute-solvent energy, $E_{\mathrm{SS}}$ is the solvent-solvent energy, and $E_{\mathrm{SS}}^{*}$ is the solvent-solvent energy in the pure liquid. $V^{*}$ and $V$ are the volumes of the pure liquid and the solution, respectively.

$$
\begin{gathered}
H_{\mathrm{SX}}=E_{\mathrm{SX}}+E_{\mathrm{SS}}+p V \\
H_{\mathrm{SS}}^{*}=E_{\mathrm{SS}}^{*}+p V^{*}
\end{gathered}
$$

The solvation enthalpy of the gas-phase solute species $\mathrm{X}$ $\left(\mathrm{PhOH}\right.$ or $\left.\mathrm{PhO}^{\bullet}\right)$ can be calculated from eq 5 :

$$
\begin{aligned}
\Delta_{\mathrm{sln}} H(\mathrm{X}, \mathrm{g}) & =H_{\mathrm{SX}}-H_{\mathrm{SS}}^{*}-R T=E_{\mathrm{SX}}+\left(E_{\mathrm{SS}}-E_{\mathrm{SS}}^{*}\right)+ \\
& p\left(V-V^{*}\right)-R T \\
& =E_{\mathrm{SX}}+\Delta E_{\mathrm{R}}+p \Delta V_{\mathrm{R}}-R T \\
& =E_{\mathrm{SX}}+\Delta H_{\mathrm{R}}-R T
\end{aligned}
$$

Here, $\Delta H_{\mathrm{R}}=H_{\mathrm{SS}}-H_{\mathrm{SS}}^{*}$ is the solvent relaxation enthalpy, $\Delta E_{\mathrm{R}}$ is the solvent relaxation energy, and $p \Delta V_{\mathrm{R}}$ is the solvent 


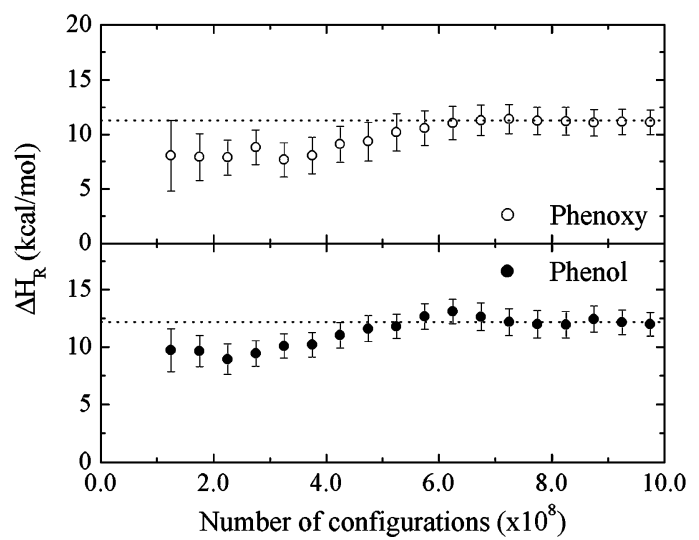

Figure 3. Convergence of the solvent relaxation energy as a function of the number of MC configurations for the simulations of phenoxy radical (top) and phenol (bottom) in acetonitrile.

TABLE 3: Thermodynamic Properties of the Pure Liquids and Solutions from NpT Monte Carlo Simulations at $T=25$ ${ }^{\circ} \mathrm{C}$ and $p=1$ atm $^{a}$

\begin{tabular}{|c|c|c|}
\hline & pure benzene & pure acetonitrile \\
\hline $\begin{array}{l}N_{\mathrm{S}} \\
R_{\mathrm{c}} \\
\rho^{*} \\
H_{\mathrm{SS}}^{*}\end{array}$ & $\begin{array}{l}216 \\
15.8 \\
0.875 \\
-1632.5 \pm 0.5\end{array}$ & $\begin{array}{l}500 \\
17.2 \\
0.842 \\
-3901.8 \pm 0.8\end{array}$ \\
\hline & phenol-benzene & phenol-acetonitrile \\
\hline $\begin{array}{l}\rho \\
E_{\mathrm{SX}} \\
H_{\mathrm{SS}} \\
\Delta_{\mathrm{sln}} H(\mathrm{PhOH}, \mathrm{g}) \\
\operatorname{exptl}^{b}\end{array}$ & $\begin{array}{l}0.875 \\
-20.20 \pm 0.01 \\
-1623.1 \pm 0.5(9.4 \pm 0.7) \\
-11.4 \pm 0.7 \\
-12.1 \pm 0.2\end{array}$ & $\begin{array}{l}0.843 \\
-26.54 \pm 0.02 \\
-3889.6 \pm 0.9(12.2 \pm 1.2) \\
-14.9 \pm 1.2 \\
-14.2 \pm 0.1\end{array}$ \\
\hline & phenoxy-benzene & phenoxy-acetronitrile \\
\hline $\begin{array}{l}\rho \\
E_{\mathrm{SX}} \\
H_{\mathrm{SS}} \\
\Delta_{\mathrm{sln}} H(\mathrm{PhO}, \mathrm{g})\end{array}$ & $\begin{array}{l}0.876 \\
-19.02 \pm 0.23 \\
-1624.8 \pm 0.7(7.7 \pm 0.9) \\
-11.9 \pm 0.9\end{array}$ & $\begin{array}{l}0.843 \\
-25.05 \pm 0.04 \\
-3890.5 \pm 0.7(11.3 \pm 1.1) \\
-14.3 \pm 1.1\end{array}$ \\
\hline
\end{tabular}

${ }^{a} N_{\mathrm{S}}$ is the number of solvent molecules; $R_{\mathrm{c}}$ is the cutoff distance (in $\AA$ ) for the interactions between the solute (X) and the solvent (S); $H_{\mathrm{SS}}=E_{\mathrm{SS}}+p V$ is the enthalpy of the solvent in the solution, and $H_{\mathrm{SS}}^{*}$ $=E_{\mathrm{SS}}^{*}+p V$ is the enthalpy of pure solvent $\left(E_{\mathrm{SS}}^{*}\right.$ and $V^{*}$ represent, respectively, the energy and the volume of the pure solvent); $\rho^{*}$ and $\rho$ are, respectively, the densities (in $\mathrm{g} \mathrm{cm}^{-3}$ ) of the pure solvent and solution; $\Delta_{\sin } H(\mathrm{X}, \mathrm{g})=E_{\mathrm{SX}}+\Delta H_{\mathrm{R}}-R T$ is the solvation enthalpy of the solute species $\mathrm{X}$. Values in parentheses are solvent relaxation enthalpies $\left(\Delta H_{\mathrm{R}}=H_{\mathrm{SS}}-H_{\mathrm{SS}}^{*}\right)$. Energy and enthalpy values are in kcal mol ${ }^{-1} \cdot{ }^{b}$ Experimental value of $\Delta_{\mathrm{sln}} H(\mathrm{PhOH}, \mathrm{g})$. See text.

relaxation volume contribution to the solvation enthalpy, which is negligible under normal conditions. The estimation of solvation enthalpies from eq 5 is difficult because of the slow convergence of the solvent relaxation enthalpy $\left(\Delta H_{\mathrm{R}}\right)$, calculated as the difference between two large and fluctuating numbers. ${ }^{48,49}$ The convergence of this quantity as a function of the number of MC steps is illustrated in Figure 3 for the case of acetonitrile as solvent. The convergence is obtained after ca. $6 \times 10^{8} \mathrm{MC}$ steps. However, it is interesting to note that the solvent relaxation is sizable both for phenol and phenoxy radical but the differential relaxation enthalpy nearly cancels. Hence, although both solutes induce significant solvent reorganization energies $(12.2 \pm 1.2$ $\mathrm{kcal} \mathrm{mol}{ }^{-1}$ for phenol and $11.3 \pm 1.1 \mathrm{kcal} \mathrm{mol}^{-1}$ for the phenoxy radical), the contribution to the differential enthalpy is mild. A similar result is obtained in the case of benzene as solvent.

Table 3 reports the thermodynamic data obtained from the MC simulations of the pure liquids and solutions. The solvation enthalpy of phenol in benzene, $\Delta_{\mathrm{sln}} H^{\circ}(\mathrm{PhOH}, \mathrm{g})$, predicted by the simulations $\left(-11.4 \pm 0.7 \mathrm{kcal} \mathrm{mol}^{-1}\right)$ is in good agreement with the experimental result $\left(-12.1 \pm 0.2 \mathrm{kcal} \mathrm{mol}^{-1}\right)$. This value was obtained by subtracting the standard enthalpy of sublimation of phenol $\left(16.42 \pm 0.12 \mathrm{kcal} \mathrm{mol}^{-1}\right)^{50}$ from the enthalpy of solution of phenol in benzene $(4.30 \pm 0.14 \mathrm{kcal}$ $\mathrm{mol}^{-1}$ ) measured by reaction-solution calorimetry.

For the solvation of phenoxy in benzene, the Monte Carlo simulation led to $\Delta_{\mathrm{sln}} H^{\circ}\left(\mathrm{PhO}^{\circ}, \mathrm{g}\right)=-11.9 \pm 0.9 \mathrm{kcal} \mathrm{mol}^{-1}$. The surprising feature of this result, taken together with the one above for phenol, is that the differential solvation enthalpy, $\Delta_{\text {sln }} H^{\circ}(\mathrm{PhOH}, \mathrm{g})-\Delta_{\mathrm{sln}} H^{\circ}\left(\mathrm{PhO}^{\circ}, \mathrm{g}\right)$, in benzene is quite small: within the estimated error bars, the solvation enthalpies of phenol and phenoxy radical in benzene are identical.

The MC result for $\Delta_{\mathrm{sln}} H^{\circ}(\mathrm{PhOH}, \mathrm{g})$ in acetonitrile is -14.9 $\pm 1.2 \mathrm{kcal} \mathrm{mol}^{-1}$, in very good agreement with the experimental value, $-14.2 \pm 0.1 \mathrm{kcal} \mathrm{mol}^{-1}$ (obtained from the sublimation enthalpy of phenol given above and the measured enthalpy of solution of phenol in acetonitrile, $2.20 \pm 0.05 \mathrm{kcal} \mathrm{mol}^{-1}$ ). Finally, our theoretical prediction for the solvation enthalpy of the phenoxy radical in acetonitrile is $-14.3 \pm 1.1 \mathrm{kcal} \mathrm{mol}^{-1}$, implying that the $\mathrm{MC}$ method predicts $\Delta_{\mathrm{sln}} H^{\circ}(\mathrm{PhOH}, \mathrm{g})-$ $\Delta_{\text {sln }} H^{\circ}\left(\mathrm{PhO}^{\circ}, \mathrm{g}\right)=-0.5 \pm 1.1 \mathrm{~kJ} \mathrm{~mol}^{-1}$.

The very good agreement between the theoretical and experimental solvation enthalpies of phenol in both benzene and acetonitrile is a clear indication of the reliability of the present modeling of the solute-solvent interactions. This supports the predictions of the solvation enthalpies for the phenoxy radical.

PhO-H Bond Dissociation Enthalpy. The experimental values obtained from the TR-PAC experiments for $D H_{\sin ^{-}}$$(\mathrm{PhO}-\mathrm{H})$ in benzene and in acetonitrile are $90.9 \pm 1.3$ and $92.9 \pm 0.9 \mathrm{kcal} \mathrm{mol}^{-1}$, respectively. As explained at the Introduction, both results rely on the estimate $\Delta_{\mathrm{sln}} H^{\circ}\left(\mathrm{H}^{\bullet}, \mathrm{g}\right)=$ $1.2 \pm 0.2 \mathrm{kcal} \mathrm{mol}^{-1},{ }^{8}$ which in turn relies on the assumption that the solvation enthalpies of the hydrogen atom and the hydrogen molecule are similar. ${ }^{51}$ In a recent study, we have obtained the enthalpy of hydration for the hydrogen atom using a classical MC simulation. ${ }^{23}$ The result was indeed in good agreement with the experimental value for the hydration of $\mathrm{H}_{2}$. A similar procedure was adopted here to obtain an independent estimate of the enthalpy of solvation of $\mathrm{H}^{\bullet}$. In acetonitrile, we found that $\Delta_{\mathrm{sln}} H^{\circ}\left(\mathrm{H}^{\bullet}, \mathrm{g}\right)=1.39 \pm 0.84 \mathrm{kcal} \mathrm{mol}^{-1}$ and $\Delta_{\mathrm{sln}} H^{\circ}$ $\left(\mathrm{H}_{2}, \mathrm{~g}\right)=1.32 \pm 0.66 \mathrm{kcal} \mathrm{mol}^{-1}$.

As also pointed out before (see Introduction), when the above TR-PAC results are used to derive the gas-phase $\mathrm{PhO}-\mathrm{H}$ bond dissociation enthalpy through eq 1 , the enthalpy of solvation of the hydrogen atom cancels out (provided that we take the same value used to calculate $D H_{\sin }^{\circ}(\mathrm{PhO}-\mathrm{H})$ ). Therefore, the only relevant term in eq 1 is the differential solvation enthalpy, $\Delta_{\text {sln }} H^{\circ}(\mathrm{PhOH}, \mathrm{g})-\Delta_{\mathrm{sln}} H^{\circ}\left(\mathrm{PhO}^{\circ}, \mathrm{g}\right)$. A summary of our theoretical calculations for this quantity is presented in Table 4. Here, it is noted that there is a general good agreement between the selected value for the gas-phase $\mathrm{PhO}-\mathrm{H}$ bond dissociation enthalpy, $\mathrm{DH}^{\circ}(\mathrm{PhO}-\mathrm{H})=88.7 \pm 0.5 \mathrm{kcal} \mathrm{mol}^{-1}$ (which is also in very good agreement with a recent G3(MP2) calculation, $\left.89.9 \mathrm{kcal} \mathrm{mol}^{-1}\right)^{9}$ and the computational results for the differential solvation enthalpies together with the values obtained from the TR-PAC experiments for $D H_{\sin }^{\circ}(\mathrm{PhO}-\mathrm{H})$ in benzene and in acetonitrile.

Results for $\Delta_{\mathrm{sln}} H^{\circ}(\mathrm{PhOH}, \mathrm{g})-\Delta_{\mathrm{sln}} H^{\circ}\left(\mathrm{PhO}^{\circ}, \mathrm{g}\right)$ based on ECW model $^{13}$ and on the assumption that the differential solvation enthalpy is only due to the intermolecular hydrogen bond between $\mathrm{PhOH}$ and the solvent ${ }^{11}$ are -2.1 (benzene) and -4.5 $\mathrm{kcal} \mathrm{mol}^{-1}$ (acetonitrile). Both are more negative than micro- 
TABLE 4: Differential Solvation Enthalpy, $\Delta_{\sin } H(\mathbf{P h O H}, \mathrm{g})$ - $\Delta_{\mathrm{sln}} H\left(\mathrm{PhO}^{*}, \mathrm{~g}\right)\left(\mathrm{kcal} \mathrm{mol}^{-1}\right)$ Obtained from the Microsolvation and the Monte Carlo Methods and $\mathrm{PhO}-\mathrm{H}$ Gas-Phase Bond Dissociation Enthalpies $\left(\mathrm{kcal} \mathrm{mol}^{-1}\right)$

\begin{tabular}{|c|c|c|c|}
\hline method & $\begin{array}{c}\Delta_{\mathrm{sln}} H(\mathrm{PhOH}, \mathrm{g})- \\
\Delta_{\mathrm{sln}} H\left(\mathrm{PhO}^{*}, \mathrm{~g}\right)\end{array}$ & $D H^{\circ}(\mathrm{PhO}-\mathrm{H})^{a, b}$ & $D H_{\mathrm{sln}}^{\circ}(\mathrm{PhO}-\mathrm{H})^{b, c}$ \\
\hline \multicolumn{4}{|c|}{ Benzene } \\
\hline $\begin{array}{c}\text { cluster with } \\
1 \mathrm{C}_{6} \mathrm{H}_{6}\end{array}$ & -1.0 & 88.7 & 90.9 \\
\hline $\begin{array}{l}\text { cluster with } \\
2 \mathrm{C}_{6} \mathrm{H}_{6}\end{array}$ & -1.0 & 88.7 & 90.9 \\
\hline Monte Carlo & $0.5 \pm 1.1$ & $90.2 \pm 1.6$ & $89.4 \pm 1.2$ \\
\hline ECW & -2.1 & 87.7 & 92.0 \\
\hline exptl & $-1.0 \pm 1.4^{a, b, c}$ & $88.7 \pm 0.5$ & $90.9 \pm 1.3$ \\
\hline \multicolumn{4}{|c|}{ Acetonitrile } \\
\hline $\begin{array}{l}\text { cluster with } \\
1 \mathrm{CH}_{3} \mathrm{CN}\end{array}$ & -2.1 & 89.6 & 92.0 \\
\hline $\begin{array}{l}\text { cluster with } \\
2 \mathrm{CH}_{3} \mathrm{CN}\end{array}$ & -2.7 & 89.0 & 92.7 \\
\hline Monte Carlo & $-0.6 \pm 1.6$ & $91.1 \pm 1.6$ & $90.5 \pm 1.7$ \\
\hline ECW & -4.5 & 87.2 & 94.4 \\
\hline exptl & $-3.0 \pm 1.0^{a, b, c}$ & $88.7 \pm 0.5$ & $92.9 \pm 0.9$ \\
\hline
\end{tabular}

${ }^{a}$ Calculated from eq 1 using $90.9 \pm 1.3$ and $92.9 \pm 0.9 \mathrm{kcal} \mathrm{mol}^{-1}$ for $D H_{\sin }^{\circ}(\mathrm{PhO}-\mathrm{H})$ in benzene and in acetonitrile, respectively. ${ }^{b}$ The enthalpy of solvation of the hydrogen atom was taken as $1.2 \mathrm{kcal} \mathrm{mol}^{-1}$ in both solvents. ${ }^{c}$ Obtained from eq 1 using the recommended gasphase value, $D H^{\circ}(\mathrm{PhO}-\mathrm{H})=88.7 \pm 0.5 \mathrm{kcal} \mathrm{mol}^{-1}$.

solvation or Monte Carlo predictions, particularly in the case of acetonitrile (Table 4). Therefore, the ECW predictions clearly overestimate the solvent effect, mainly in the case of the polar solvent.

An alternative way of looking into our results (which is more appropriate for a computational chemist who usually calculates gas-phase data) is using the recommended gas-phase $\mathrm{PhO}-\mathrm{H}$ bond dissociation enthalpy, together with the microsolvation or the Monte Carlo results, to predict $D H_{\mathrm{sln}}^{\circ}(\mathrm{PhO}-\mathrm{H})$. It is observed in Table 4 that the theoretical predictions for $\Delta_{\sin } H^{\circ}$ $(\mathrm{PhOH}, \mathrm{g})-\Delta_{\sin } H^{\circ}\left(\mathrm{PhO}^{\circ}, \mathrm{g}\right)$ lead to a general good agreement with experiment. For example, using the microsolvation approach, $D H_{\mathrm{sln}}^{\circ}\left(\mathrm{PhO}-\mathrm{H}\right.$ ) in benzene is $90.9 \mathrm{kcal} \mathrm{mol}^{-1}$ (which coincides with experiment), and the Monte Carlo prediction is $89.4 \pm 1.2 \mathrm{kcal} \mathrm{mol}^{-1}$. In acetonitrile, the Monte Carlo result is $90.5 \pm 1.7 \mathrm{kcal} \mathrm{mol}^{-1}$, in fair agreement with experiment $\left(92.9 \pm 0.9 \mathrm{kcal} \mathrm{mol}^{-1}\right)$. The microsolvation result for the cluster with two acetonitrile molecules $\left(92.7 \mathrm{kcal} \mathrm{mol}^{-1}\right)$ is also in keeping with the experimental value.

Interestingly, although the microsolvation approach does not take into account the solvent relaxation contributions, it predicts a $D H_{\mathrm{sln}}^{\circ}(\mathrm{PhO}-\mathrm{H})$ value in very good agreement with experiment. For the present systems, the difference between the solvent relaxation enthalpies of phenol and phenoxy radical is very small. If it is neglected, microsolvation and Monte Carlo results are very close. However, we stress that the agreement is very dependent on the recommended value for $D H^{\circ}(\mathrm{PhO}-\mathrm{H})$. If we take the G3(MP2) value for this quantity $\left(89.9 \mathrm{kcal} \mathrm{mol}^{-1}\right)$, which is only $1.2 \mathrm{kcal} \mathrm{mol}^{-1}$ above the recommended experimental value, then the Monte Carlo results are much closer to experiment.

There are not many compounds for which bond enthalpy data are available both in solution and in the gas phase. On the other hand, although computational thermochemistry has reached a stage where the results rival in accuracy with those obtained from experiments, ${ }^{52}$ most in-silico studies involve the isolated molecule (ideal gas phase). It is thus important to develop theoretical methodologies to bridge the data for those two physical states, because they will afford accurate thermochemical values also in solution. The data in Table 4 seem to confirm that the theoretical approaches used in our studies are in keeping with that goal, although not quite reaching "chemical accuracy" (ca. $1 \mathrm{kcal} \mathrm{mol}^{-1}$ ).

The second general conclusion that can be drawn from the data in Table 4 is that the solution- and the gas-phase bond dissociation enthalpy values are much closer to each other than anticipated. In fact, $\Delta_{\mathrm{sln}} H^{\circ}(\mathrm{PhOH}, \mathrm{g})-\Delta_{\mathrm{sln}} H^{\circ}(\mathrm{PhO}, \mathrm{g})$ could be expected to be small in nonpolar solvents such as benzene, under the reasonable assumption that the interactions of phenol and phenoxy radical with benzene are very similar. Even if the differential solvation enthalpy is identified with the intermolecular hydrogen bond between phenol and benzene, the difference $D H^{\circ}(\mathrm{PhO}-\mathrm{H})-D H_{\mathrm{sln}}^{\circ}(\mathrm{PhO}-\mathrm{H})$ would be less than ca. $-3 \mathrm{kcal} \mathrm{mol}^{-1} 11$ (compared with $-2.2 \pm 1.4 \mathrm{kcal} \mathrm{mol}^{-1}$ from the experimental data in Table 4). However, for a solvent like acetonitrile, which is able to form strong hydrogen bonds with phenol, we were not expecting a small correction for the differential solvation energetics: the same assumption ${ }^{11}$ would lead to $D H^{\circ}(\mathrm{PhO}-\mathrm{H})-D H_{\mathrm{sln}}^{\circ}(\mathrm{PhO}-\mathrm{H}) \approx-6 \mathrm{kcal} \mathrm{mol}^{-1}$ $\left(-4.2 \pm 1.0 \mathrm{kcal} \mathrm{mol}^{-1}\right.$ from experiment). Such assumption neglects several important aspects, such as the stabilization of the phenoxy radical by the solvent and the solvent relaxation that is induced by the presence of the solute.

Recalling eqs 1 and 5, we can also write the solvent contribution to the bond dissociation enthalpy (eq 1) as

$$
\begin{aligned}
& D H^{\circ}(\mathrm{PhO}-\mathrm{H})-D H_{\mathrm{sln}}^{\circ}(\mathrm{PhO}-\mathrm{H})= \\
& \Delta E_{\mathrm{SX}}+\Delta \Delta H_{\mathrm{R}}-\Delta_{\mathrm{sln}} H^{\circ}\left(\mathrm{H}^{\bullet}, \mathrm{g}\right)
\end{aligned}
$$

The influence of the solvent on the bond dissociation enthalpy difference will be negligible if the change in the solute-solvent interaction energy, $\Delta E_{\mathrm{SX}}=E_{\mathrm{SX}}(\mathrm{PhOH})-E_{\mathrm{SX}}\left(\mathrm{PhO}^{*}\right)$, and the change in the solvent relaxation enthalpy, $\Delta \Delta H_{\mathrm{R}}=\Delta H_{\mathrm{R}}(\mathrm{PhOH})$ $-\Delta H_{\mathrm{R}}\left(\mathrm{PhO}^{\circ}\right)$, are very small. These terms will partially cancel each other because the former is expected to be negative whereas $\Delta \Delta H_{\mathrm{R}}$ will be positive (see Table 3). As mentioned above,

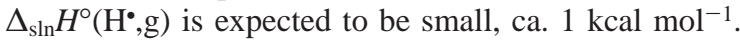

Figure 4 shows the behavior of the solute-solvent interaction energy as a function of the center-of-mass distance from the solute, $E_{\mathrm{SX}}(r)$. These averages were calculated over 400 uncorrelated configurations. The inset shows the phenol-phenoxy change, $\Delta E_{\mathrm{SX}}(r)$, which is the term contributing to the solvent effect in eq 6 . When phenol or phenoxy radical are solvated in benzene (top of Figure 4), we can see that $E_{\mathrm{SX}}(r)$ converges at $r \approx 12.5 \AA$. However, $\Delta E_{\mathrm{SX}}(r)$ converges at a much shorter distance, $r \approx 7.7 \AA$ (inset of Figure 4 , top). This corresponds precisely to the position of the first minimum of the center-ofmass radial distribution function of phenol and phenoxy radical in benzene (see section Structure), strongly suggesting that the contribution of the solute-solvent interaction to the differential solvent effect can be correctly estimated by considering only the interactions between the solute (phenol or phenoxy radical) and the solvent molecules in the first coordination shell. In the present case, this corresponds to 13 benzene molecules. Figure 4 (top inset) also shows that including only a few benzene molecules of the first coordination shell leads to an overestimate of $\Delta E_{\mathrm{SX}}$.

The behavior of the solute-solvent interaction $E_{\mathrm{SX}}$ for phenol and phenoxy radical in the case of acetonitrile is quite different (bottom of Figure 4). Our results clearly show that, in this case, $E_{\mathrm{SX}}(r)$ converges only at a larger distance $r \approx 17.0 \AA$. Moreover, $\Delta E_{\mathrm{SX}}(r)$ also converges at nearly the same distance. The analysis of the center-of-mass radial distribution function indicates that 


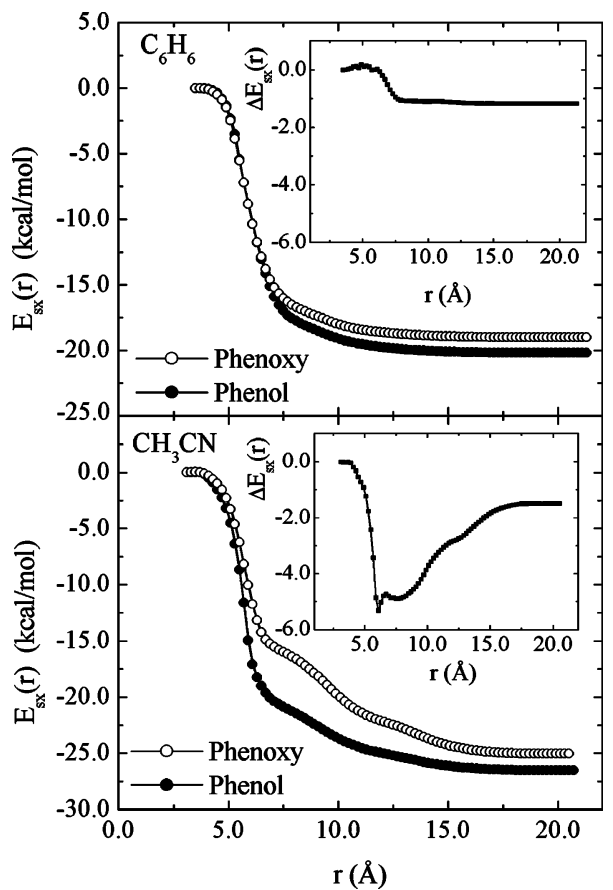

Figure 4. Average solute-solvent energy as a function of the centerof-mass distance to the solute, $E_{\mathrm{SX}}(r)$, for the simulations of phenol and phenoxy radical in benzene (top) and acetonitrile (bottom). Insets show $\Delta E_{\mathrm{SX}}(r)$, the difference between $E_{\mathrm{SX}}(r)$ values for phenol and phenoxy radical, as a function of the center-of-mass distance to the solute.

this corresponds to 250 acetonitrile molecules. The inset now shows that $\Delta E_{\mathrm{SX}}(r)$ has a more complex behavior. Even considering all solvent molecules within the first solvation shell, corresponding to $r=7.0 \AA$, the differential solute-solvent interaction is far from the converged value. The hydrogen bond that occurs in the solute-solvent interaction is different for phenol and phenoxy radical, and this leads to a more negative $\Delta E_{\mathrm{SX}}$ at the center-of-mass distance of $6.0 \AA$, compared to the converged value. This observation reveals yet another aspect not contemplated by the simplifying assumption above, where the differential solvation enthalpy, $\Delta_{\sin } H^{\circ}(\mathrm{PhOH}, \mathrm{g})-\Delta_{\mathrm{sln}} H^{\circ}$ $\left(\mathrm{PhO}^{*}, \mathrm{~g}\right)$, is identified with the enthalpy of the $\mathrm{PhOH} \cdots \mathrm{S}$ hydrogen bond. The long-range behavior of $E_{\mathrm{SX}}(r)$ in the case of acetonitrile relates to the dipolar interactions between the polar solute and the polar solvent molecules. A similar conclusion was also obtained from solvatochromic shifts in UVvisible spectra. Whereas the red shift of the first absorption transition of benzene in water is converged by including only the first solvation shell, ${ }^{53}$ the case of formaldehyde in water requires the inclusion of the outer solvation shells. ${ }^{54,55}$ Therefore, it seems safe to conclude that the solute-solvent interaction for the case of a polar solute in a polar solvent extends to a long range. Hence, our results indicate that a microsolvation approach is still not able to correctly model the solvation in the general case, although it should be recognized that the numerical error involved is not large. Moreover, when the microsolvation method is applied to estimate a differential solvation enthalpy (as in our case), the errors caused by considering a small number of solvent molecules are likely to partially cancel. ${ }^{56}$

At the origin of the small value for $\Delta_{\mathrm{sln}} H^{\circ}(\mathrm{PhOH}, \mathrm{g})-\Delta_{\mathrm{sln}} H^{\circ}$ $\left(\mathrm{PhO}^{*}, \mathrm{~g}\right)$ is the dipole moment of the solute. Because the dipole moment of the phenoxy radical is considerably larger than the dipole moment of phenol, one could be lead to expect that the radical would be significantly more stabilized by the solvent than phenol, leading to a decrease in $\mathrm{DH}_{\mathrm{sln}}^{\circ}(\mathrm{PhO}-\mathrm{H})$ (Katritz- ky et al. emphasized the importance of solvent effects in differential solvation when the radical formed in the reaction has a larger dipole moment than the reactant) ${ }^{57}$ In other words, the bond dissociation enthalpy in solution would be smaller than the gas-phase value, $D H^{\circ}(\mathrm{PhO}-\mathrm{H})$. Yet, this is in clear contrast with the present experimental and theoretical results.

As Figure 4 shows, the solute-solvent interaction energy is less negative for the phenoxy radical than for phenol in both solvents. Let us consider first the case of acetonitrile. For short solute-solvent distances, the phenol-acetonitrile hydrogen bond is stronger than the phenoxy-acetonitrile interaction, so this partially compensates for the smaller dipole moment of phenol. Indeed, the phenol-acetonitrile interaction is ca. 2.0 $\mathrm{kcal} \mathrm{mol}^{-1}$ stronger than the phenoxy-acetonitrile interaction (Table 2). For benzene, the interaction of the first molecule is also stronger for phenol than for phenoxy. However, a second aspect is needed to explain the long range behavior in the case of acetonitrile. We contend that for larger distances from the solute molecule the solvent molecules interact significantly with the dipole moment of the hydrogen-bonded complex, phenolacetonitrile or phenoxy-acetonitrile. Thus we should compare not the dipole moments of gas-phase phenol and phenoxy radical but the dipole moments of the hydrogen-bonded complexes phenol-acetonitrile and phenoxy-acetonitrile. Using the configurations generated by the MC simulation, we extracted 45 uncorrelated configurations, composed of the solute and the hydrogen-bonded solvent, using a procedure that has been successfully used before. ${ }^{58}$ Subsequent quantum mechanical calculations of the dipole moment of the complex was performed at the B3LYP/6-31+G(d,p) level. The results indicate that the dipole moments are similar: $6.4 \pm 0.6 \mathrm{D}$ for phenol-acetonitrile and $6.9 \pm 1.8 \mathrm{D}$ for phenoxy radical. The larger variation in the case of phenoxy reflects the larger possibilities of hydrogenbond structures in this case.

Our MC results confirm that the net solvent effects on the $\mathrm{PhO}-\mathrm{H}$ bond enthalpy are small for the solvation in benzene and in acetonitrile. In the case of benzene, we see in Table 3 that both the average solute-solvent energies $\left(E_{\mathrm{SX}}\right)$ for phenol and phenoxy radical $(-20.20 \pm 0.01$ and $-19.02 \pm 0.23 \mathrm{kcal}$ $\mathrm{mol}^{-1}$, respectively) and the solvent relaxation enthalpies, $\Delta H_{\mathrm{R}}$, are very similar $\left(9.4 \pm 0.7\right.$ and $7.7 \pm 0.9 \mathrm{kcal} \mathrm{mol}^{-1}$, respectively). These results imply that $\Delta_{\text {sln }} H^{\circ}(\mathrm{PhOH}, \mathrm{g})-$ $\Delta_{\text {sln }} H^{\circ}\left(\mathrm{PhO}^{\circ}, \mathrm{g}\right)$ is close to zero and the net solvent contribution on the $\mathrm{PhO}-\mathrm{H}$ becomes very small (Table 4).

For acetonitrile, the solvent contribution, as predicted by the MC calculations, is also small, amounting to less than $1 \mathrm{kcal}$ $\mathrm{mol}^{-1}$. Again, this is related to the small difference between the average solute-solvent interaction energies, $E_{\mathrm{SX}}$, of phenol and phenoxy radical with acetonitrile $\left(\Delta E_{\mathrm{SX}}=-1.5 \mathrm{kcal}\right.$ $\left.\mathrm{mol}^{-1}\right)$. Solvent relaxation energies are also very similar $(12.2$ \pm 1.2 and $11.3 \pm 1.1 \mathrm{kcal} \mathrm{mol}^{-1}$, respectively), leading to a contribution of only $0.9 \mathrm{kcal} \mathrm{mol}^{-1}$ for $\Delta \Delta H_{\mathrm{R}}$ (eq 9).

Before concluding this section, we should mention that the previous cases, involving benzene and acetonitrile, are different from the case of phenol and phenoxy radical in water, where the solvent increases the bond dissociation enthalpy compared to the gas-phase value by as much as $7 \mathrm{kcal} \mathrm{mol}^{-1}$. In water, most of the solvent effect derives from the difference in solutesolvent interaction. ${ }^{23}$

Differential Solvation Gibbs Energy of Phenol and Phenoxy Radical in Benzene and Acetonitrile. We have used thermodynamic perturbation theory ${ }^{24-27}$ to evaluate the difference between the solvation Gibbs energy of phenol and phenoxy radical. The method is based on the following relation for the 
TABLE 5. Gibbs Energy Differences (kcal mol-1) for Phenol $(i) \leftrightarrow$ Phenoxy Radical $(j)$ "Interconversion" in Benzene and Acetonitrile at $25{ }^{\circ} \mathrm{C}$

\begin{tabular}{|c|c|c|c|c|c|}
\hline \multirow[b]{2}{*}{$\lambda_{i}$} & \multirow[b]{2}{*}{$\lambda_{j}$} & \multicolumn{2}{|c|}{ benzene } & \multicolumn{2}{|c|}{ acetonitrile } \\
\hline & & $\Delta G(i \rightarrow j)$ & $\Delta G(j \rightarrow i)$ & $\Delta G(i \rightarrow j)$ & $\Delta G(j \rightarrow i)$ \\
\hline 0.0 & 0.125 & 0.455 & -0.471 & 1.643 & -1.875 \\
\hline 0.125 & 0.250 & 0.259 & -0.262 & 1.167 & -1.255 \\
\hline 0.250 & 0.375 & 0.125 & -0.180 & 0.895 & -0.742 \\
\hline 0.375 & 0.500 & 0.066 & -0.044 & 0.317 & -0.379 \\
\hline 0.500 & 0.625 & -0.057 & 0.082 & -0.012 & 0.069 \\
\hline 0.625 & 0.750 & -0.161 & 0.127 & -0.403 & 0.619 \\
\hline 0.750 & 0.875 & -0.200 & 0.211 & -0.916 & 0.758 \\
\hline 0.875 & 1.0 & -0.274 & 0.255 & -1.027 & 1.160 \\
\hline total & & $0.21 \pm 0.16$ & $-0.28 \pm 0.17$ & $1.66 \pm 0.32$ & $-1.64 \pm 0.30$ \\
\hline
\end{tabular}

Gibbs energy difference between systems $i$ and $j$ :

$$
\Delta G(i \rightarrow j)=G_{j}-G_{i}=-k_{\mathrm{B}} T \ln \left\langle\exp \left[-\left(H_{j}-H_{i}\right) /\left(k_{\mathrm{B}} T\right)\right]\right\rangle
$$

where the average corresponds to sampling using system $i$.

If $\xi$ denotes a geometric or potential function parameter, a coupling parameter $\lambda$ connecting systems $i$ and $j$ can be defined as

$$
\xi(\lambda)=\xi_{i}+\lambda\left(\xi_{j}-\xi_{i}\right)
$$

The connection between systems $i$ and $j$ is then possible by mutating one system to another as $\lambda$ goes from 0 to 1 . In our simulations, phenol is mutated into phenoxy radical by scaling the charges reported in Table 1 according to eq 8 . It was assumed that the geometry and the Lennard-Jones parameters of the solutes are not modified during the mutation. This assumption means that the main difference between the solvation of phenol and phenoxy radical should be related to electrostatic interactions. It is important to note that the hydrogen atom of the phenol $\mathrm{OH}$ group is represented in the simulation only by the Coulomb charge (see Table 1). Therefore, the $\mathrm{H}$ atom vanishes when the charge becomes zero. The coupling parameter $\lambda$ can be also very useful to analyze the modifications on the solute-solvent correlations when phenol $(\lambda=0)$ mutates into phenoxy $(\lambda=1)$. This analysis is made below, starting with the case of acetonitrile as solvent. Gibbs energy differences during the mutation are reported in Table 5. The hysteresis of the results is quite small, reflecting that the $\Delta \lambda$ 's are adequate. We predict that for the "interconversion" of phenol to phenoxy radical in benzene $\Delta_{\text {solv }} G$ is quite small $(0.21 \pm 0.16 \mathrm{kcal}$ $\left.\mathrm{mol}^{-1}\right)$. For the solvation in acetonitrile, we find that $\Delta_{\text {solv }} G=$ $1.66 \pm 0.32 \mathrm{kcal} \mathrm{mol}^{-1}$. Experimental results are apparently not available for comparison.

Structure. The structure of the solutions of phenol and phenoxy radical in benzene and acetonitrile can be discussed in terms of the radial distribution function (RDF). ${ }^{35}$ The partial RDF $G_{\alpha \beta}(r)$ describes the correlation between two sites $\alpha$ (at the origin) and $\beta$ at a distance $r$ from $\alpha$. Let $V(r, \Delta r)$ be the volume of a spherical shell of radius $r$ and thickness $\Delta r$ centered at $\alpha$ and $N_{\beta}(r, \Delta r)$ the average number of sites $\beta$ in this shell. $G_{\alpha \beta}(r) \equiv \rho_{\beta}(r) / \rho$, where $\rho_{\beta}(r)=\left\langle N_{\beta}(r, \Delta r)\right\rangle / V(r, \Delta r)$ and $\rho=$ $N / V$ is the average number density of the system. Figure 5 shows the center-of-mass $(\mathrm{cm}-\mathrm{cm}) \mathrm{RDF}$ of the conversion from phenol $(\lambda=0)$ to phenoxy radical $(\lambda=1)$ in acetonitrile. Although only the limit cases of $\lambda=0$ and $\lambda=1$ have physical significance, the plot is illustrative to see the structural change during the conversion. The RDFs are indeed very similar and do not show sensitive changes from phenol to phenoxy. Only a minor shoulder can be seen around $r=3.9 \AA$, reflecting the organization of the acetonitrile molecules around the phenol $\mathrm{OH}$ group. A similar but more pronounced shoulder could also be

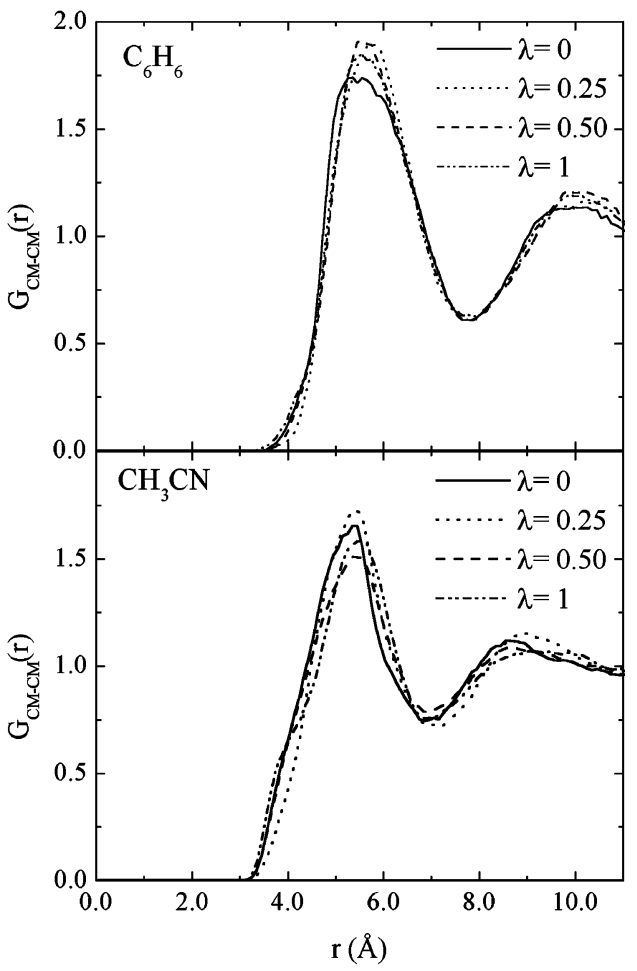

Figure 5. Center-of-mass radial distribution functions $G_{\mathrm{CM}-\mathrm{CM}}(r)$ as a function of the mutating parameter $\lambda$ from phenol $(\lambda=0)$ to phenoxy radical $(\lambda=1)$ in benzene (top) and in acetonitrile (bottom).

observed in the case of phenol in water, studied previously. ${ }^{23}$ For all $\lambda$ values, the RDF is characterized by the presence of a strong peak centered at $r=5.45 \AA$ for phenol and slightly shifted to $r=5.55 \AA$ in the case of phenoxy. Spherical integration of these functions up to the first minimum $(7.0 \AA)$ yields 17 molecules, which is the number of acetonitrile molecules in first coordination shell of phenol. As the solute molecule is converted from phenol to phenoxy radical, the coordination number changes by less than one solvent molecule. Overall, these results confirm that the outer molecules of solvent are structured much the same for phenol and phenoxy radical. Most of the possible changes can be seen only in the hydrogenbond coordination. In the case of phenol, the $\mathrm{OH}$ group can form hydrogen bonds by acting both as a hydrogen donor and as a hydrogen acceptor. In the case of the phenoxy radical only the hydrogen acceptor site of this group remains. Figure 6 shows the RDF $G_{\mathrm{H}_{x}-\mathrm{N}}(r)$, which represents the partial radial distribution functions describing the correlations between the mutating hydrogen atom of phenol $\mathrm{OH}$ group and the nitrogen atom of acetonitrile. The first peak of this function is an intense and sharp maximum starting at $r=1.55 \AA$, ending at $r=2.55 \AA$, and reaching the value of 4.9 when $\lambda=0$. This reflects the $\mathrm{H} \cdots \mathrm{N}$ hydrogen-bond interaction between the hydrogen in the 


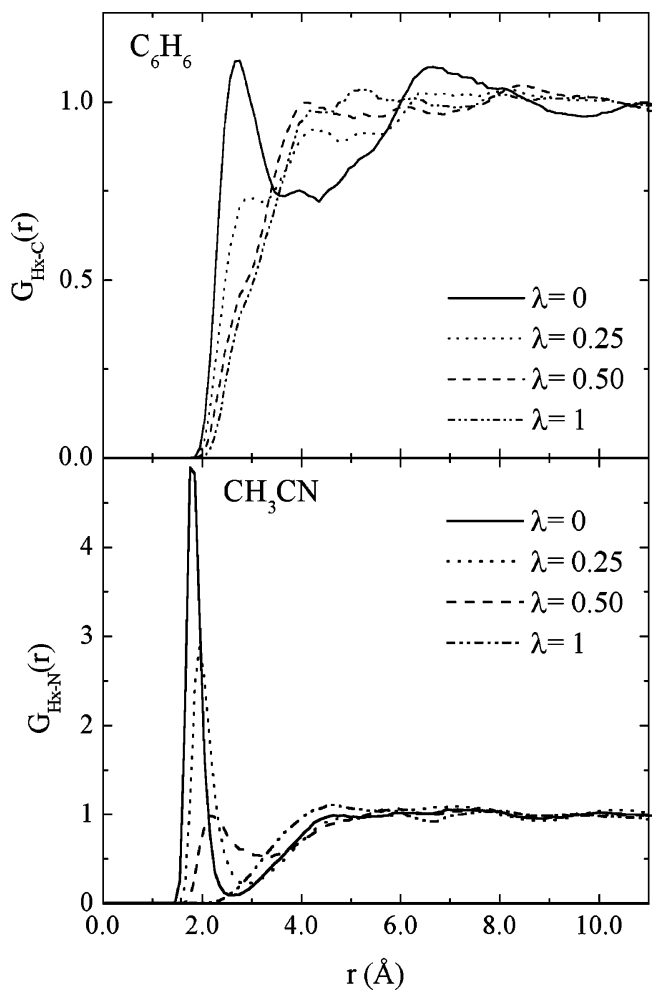

Figure 6. Solute-solvent $G_{\mathrm{H}_{x}-\mathrm{C}}(r)$ radial distribution function between the mutating hydrogen and the benzene carbon atom (top) and solutesolvent $G_{\mathrm{H}_{x}-\mathrm{N}}(r)$ radial distribution function between the mutating hydrogen and the acetonitrile nitrogen atom (bottom) as a function of $\lambda$.

phenol $\mathrm{OH}$ group and the acetonitrile molecules. The maximum shows an interesting behavior as a function of $\lambda$ : it is shifted to the right and drops quickly toward zero when $\lambda$ increases. For $\lambda=0.25$, the function is similar to the case of $\lambda=0$ but less intense (the maximum reaches the value of 2.9) and similarly for $\lambda=0.5$ (maximum at 1.0 ). For $\lambda=1.0$, the maximum disappears and now a broad distribution centered at $4.6 \AA$ can be observed. Note that the change in $\lambda$ also leads to a broadening of the RDF first peak, which entirely compensates for the decrease in intensity. Spherical integration of these peaks give essentially the value of 1.0 for the $\lambda$ values considered. We conclude that the number of $\mathrm{H}_{x} \cdots \mathrm{N}$ hydrogen bonds formed is constant during the early stages $(\lambda \leq 0.5)$ of the "interconversion" of phenol into phenoxy radical, until it totally disappears for the phenoxy case.

Figure 7 shows the RDF between the oxygen of phenol or phenoxy radical and the hydrogen atom of acetonitrile, $G_{\mathrm{O}_{x}-\mathrm{H}}(r)$. As before, when $\lambda=0$, this function describes the correlation between the oxygen atom of the phenol $\mathrm{OH}$ group and the hydrogen atoms of acetonitrile. When $\lambda=1$, the RDF describes the correlation between the oxygen atom of the phenoxy radical and the hydrogen atoms of acetonitrile. In all cases, a first coordination corresponding to the hydrogen bond shells is easily discernible. As $\lambda$ increases, corresponding to the change from phenol to phenoxy radical, the number of nearby molecules also increases. In part, this is due to the elimination of the $\mathrm{OH}$ group hydrogen. Repulsive interactions between this atom and the acetonitrile hydrogen atoms may hinder access to the $\mathrm{O}$ site in the case of phenol. The total number of molecules in this solvation shell changes from 1.3 (phenol) to 1.9 (phenoxy radical). For phenol, the RDF exhibits a first coordination shell ranging from 2.0 to $3.35 \AA$ and presents a maximum of 1.0 at $r=2.55 \AA$. Spherical integration up to the first minimum at $r$ $=3.35 \AA$ yields 1.3 , which is the average number of acetonitrile

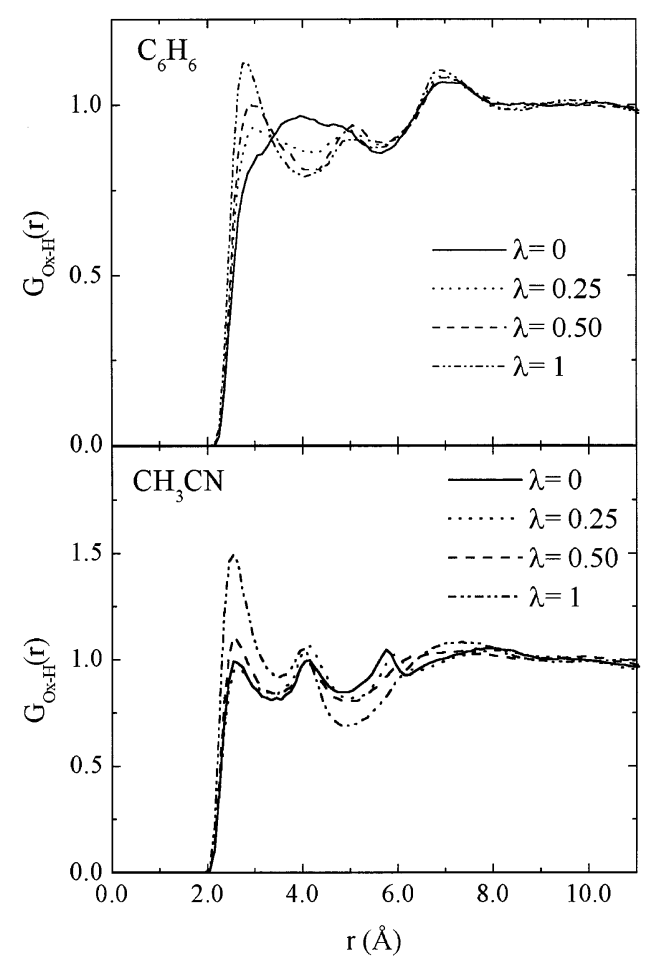

Figure 7. Solute-solvent $G_{\mathrm{O}_{x}-\mathrm{H}}(r)$ radial distribution function between the mutating oxygen atom and the hydrogen atom of benzene (top)and of acetonitrile (bottom) as a function of $\lambda$.

molecules in close interaction with the phenol $\mathrm{OH}$ group. When $\lambda$ increases, the local order around the $\mathrm{OH}$ group is significantly modified and the maximum of $G_{\mathrm{O}_{x}-\mathrm{H}}(r)$ increases considerably, leading to an increased coordination number. For $\lambda=0,0.25$, 0.5 , and 1.0 , the coordination numbers are, respectively, 1.3 , 1.4, 1.7, and 1.9. This behavior when the solute mutates from phenol to phenoxy radical indicates that the differential solvation of phenol-phenoxy involves some reorganization around the oxygen atom of the solute.

We now analyze the solvation structure in the case of benzene. Contrary to acetonitrile, benzene is a nonpolar solvent and, also very importantly, a weak hydrogen donor. Figure 5 shows the RDF for the center-of-mass distance. The first peak is relatively stable for the different $\lambda$ values with maximum of $1.74(\lambda=0)$ and $1.85(\lambda=1)$. The structures of these peaks are similar, and they all end at $r=7.75 \AA$ with a coordination number of 13 benzene molecules. These RDF are indeed very similar and do not show sensitive changes from phenol to phenoxy radical. Figure 6 shows the RDF $G_{\mathrm{H}_{x}-\mathrm{C}}(r)$ that describes the correlation between the hydrogen atom of phenol $(\lambda=0)$ $\mathrm{OH}$ group and the carbon atoms of benzene. It shows a peak centered at $r=2.75 \AA$. Spherical integration of this peak up to its minimum at $r=3.65 \AA$ gives a coordination of 1.0 , indicating some important structure close to the hydrogen atom of phenol. Figure 1a illustrates one of these structures where the hydrogen atom of phenol interacts directly with the center of mass of the nearby benzene molecule. As $\lambda$ changes from zero, this structure completely disappears, and of course, it cannot persist in the case of phenoxy radical.

In complement, Figure 7 shows the RDF $G_{\mathrm{O}_{x}-\mathrm{H}}(r)$ involving the oxygen atom of the phenol $(\lambda=0)$ or phenoxy radical $(\lambda=$ $1)$ and the hydrogen atom of benzene. For phenoxy radical, a clear structure can be seen with a maximum at $r=2.75 \AA$. Integration up to the first minimum yields a coordination number of 1.4. For $\lambda=0$, this structure cannot be seen. This is possibly related to repulsive interactions between the hydrogen atom of 
the phenol $\mathrm{OH}$ group and the benzene hydrogen atoms. In this case, some structure only appears for larger $r$ values. The first peak for phenol is centered at $r=3.95 \AA$ from the oxygen atom of phenol.

\section{Conclusions}

Density-functional theory calculations, Monte Carlo simulations, and thermodynamic perturbation theory calculations were carried out to analyze the differences between the solvation of phenol and phenoxy radical in benzene and acetonitrile. The theoretical results for the solvation of phenol in benzene and acetonitrile were complemented by time-resolved photoacoustic and isoperibol reaction-solution calorimetry measurements of solution-phase bond dissociation enthalpies and solvation enthalpies, respectively. We found a good agreement for the solvation enthalpies of phenol between Monte Carlo $(-11.4 \pm$ $0.7 \mathrm{kcal} \mathrm{mol}^{-1}$ in benzene and $-14.9 \pm 1.2 \mathrm{kcal} \mathrm{mol}^{-1}$ in acetonitrile) and experimental $\left(-12.1 \pm 0.2 \mathrm{kcal} \mathrm{mol}^{-1}\right.$ in benzene and $-14.2 \pm 0.1 \mathrm{kcal} \mathrm{mol}^{-1}$ in acetonitrile) results. This agreement supports the reliability of the present theoretical predictions of the phenoxy radical solvation enthalpies in benzene $\left(-11.9 \pm 0.9 \mathrm{kcal} \mathrm{mol}^{-1}\right)$ and acetonitrile $(-14.3 \pm$ $\left.1.1 \mathrm{kcal} \mathrm{mol}^{-1}\right)$, from which values of the differential solvation enthalpies $\Delta_{\text {sln }} H^{\circ}(\mathrm{PhOH}, \mathrm{g})-\Delta_{\mathrm{sln}} H^{\circ}\left(\mathrm{PhO}^{\circ}, \mathrm{g}\right)$ could be derived. An alternative method of estimating this quantity, using DFT calculations applied to microclusters of $\mathrm{PhOH}$ or $\mathrm{PhO}$ and one or two solvent molecules, was also used. The results are all displayed in Table 4, and a good general agreement is observed between the theoretical predictions and the experimentally derived values for $\Delta_{\mathrm{sln}} H^{\circ}(\mathrm{PhOH}, \mathrm{g})-\Delta_{\mathrm{sln}} H^{\circ}\left(\mathrm{PhO}^{\circ}, \mathrm{g}\right)$, both in benzene and in acetonitrile.

The main conclusion from the present results is, however, that the widely adopted procedure of identifying $\Delta_{\mathrm{sln}} H^{\circ}(\mathrm{PhOH}, \mathrm{g})$ - $\Delta_{\mathrm{sin}} H^{\circ}\left(\mathrm{PhO}^{\circ}, \mathrm{g}\right)$ with the enthalpy of the hydrogen bond between $\mathrm{PhOH}$ and the solvent leads to an underestimation of the correct value (i.e., leads to a more negative value). This can be understood because the hydrogen-bond-only procedure does not take into account the energetic stabilization of the phenoxy radical due to the interactions with the solvent molecules. This stabilization is more significant in polar than in nonpolar solvents.

The convergence of the solute-solvent interactions was analyzed as a function of the distance to the solute. This analysis was important to discuss the limitations of local models such as microsolvation or hydrogen-bond-only. As a final conclusion, we observe that although the microsolvation results for the differential solvation of phenol and phenoxy radical are in good agreement with experiment, this approach should be used with caution. Our results clearly indicate that a correct description of solvation should preferentially include converged solutesolvent interactions and solvent relaxation contributions.

Acknowledgment. R. C. Guedes and C. F. Correia gratefully acknowledge the support of the Fundação para a Ciência e a Tecnologia (FCT) through PhD grants (Grants PRAXIS XXI/ BD/15920/98 and SFRH/BD/6519/2001, respectively). This work was partially supported by $\mathrm{CNPq}$ (Brazil) the bilateral FAPESP/ICCTI (Brazil-Portugal) project and by the Fundação para a Ciência e Tecnologia, Portugal (Grants POCTI/43315/ QUI/2001 and POCTI/35406/QUI/1999).

\section{References and Notes}

(1) Platz, J.; Nielsen, O. J.; Wallington, T. J.; Ball, J. C.; Hurley, M. D.; Straccia, A. M.; Schneider, W. F. J. Phys. Chem. A 1998, 102, 7964.
(2) Sibener, S. J.; Buss, R. J.; Casavecchia, P.; Hirooka, T.; Lee, Y. T. J. Chem. Phys. 1980, 72, 4341.

(3) Liu, R.; Morokuma, K.; Mebel, A. M.; Lin, M. C. J. Phys. Chem. 1996, $100,9314$.

(4) Lin, C.-Y.; Lin, M. C. J. Phys. Chem. 1986, 90, 425.

(5) Weaver, E. C. Аnnu. Rev. Plant. Physiol. 1968, 19, 283.

(6) Itoh, S.; Taki, M.; Fukuzumi, S. Coord. Chem. Rev. 2000, 198, 3.

(7) Kagan, V. E.; Tyurina, Y. Y. Ann. N. Y. Acad. Sci. 1998, 854.

(8) Borges dos Santos, R. M.; Martinho Simões, J. A. J. Phys. Chem. Ref. Data 1998, 27, 707.

(9) Couto, P. C.; Guedes, R. C.; Cabral, B. J. C.; Martinho Simões, J. A. Int. J. Quantum Chem. 2002, 86, 297 and references therein.

(10) Correia, C. F.; Guedes, R. C.; Borges dos Santos, Cabral, B. J. C.; Martinho Simões, J. A. J. Phys. Chem. A, submitted for publication, 2003

(11) Wayner, D. D. M.; Lusztyk, E.; Pagé, D.; Ingold, K. U.; Mulder,

P.; Laarhoven, L. J. J.; Aldrich, H. S. J. Am. Chem. Soc. 1995, 117, 8737.

(12) See, for example, ref 11 and references therein.

(13) (a) Drago, R. S.; Dadmun, A. P.; Vogel, G. C. Inorg. Chem. 1993, 32, 2473. (b) Vogel, G. C.; Drago, R. S. J. Chem. Educ. 1996, 73, 701707. (c) Drago, R. S. Applications of Electrostatic-Covalent Models in Chemistry; Surfside: Gainesville, FL, 1994.

(14) Borges dos Santos, R. M.; Muralha, V. S. F.; Correia, C. F.; Martinho Simões, J. A. J. Am. Chem. Soc. 2001, 123, 12670.

(15) Borges dos Santos, R. M.; Muralha, V. S. F.; Correia, C. F.; Guedes, R. C.; Cabral, B. J. C.; Martinho Simões, J. A. J. Phys. Chem. A 2002, $106,9883$.

(16) Fernandez, J. A.; Yao, J.; Bernstein, E. R. J. Chem. Phys. 1997, 107, 3363 .

(17) Fernandez, J. A.; Yao, J.; Bernstein, E. R. J. Chem. Phys. 1999 , 110,5159

(18) Yao, J.; Fernandez, J. A.; Bernstein, E. R. J. Chem. Phys. 1999, 110,5174

(19) Fernandez, J. A.; Yao, J.; Bernstein, E. R. J. Chem. Phys. 1999, $110,5183$.

(20) Bray, J. A.; Bernstein, E. R. J. Phys. Chem. A 1999, 103, 2214.

(21) Chipman, D. M. J. Phys. Chem. A 1999, 103, 11181.

(22) Guedes, R. C.; Cabral, B. J. C.; Martinho Simões, J. A.; Diogo, H. P. J. Phys. Chem. A 2000, 104, 6062.

(23) Guedes, R. C.; Coutinho, K.; Cabral, B. J. C.; Canuto, S. J. Phys. Chem. B 2003, 107, 4304.

(24) Kirkwood, J. G. J. Chem. Phys. 1935, 3, 300

(25) Zwanzig, R. W. J. Chem. Phys. 1954, 22, 1420

(26) Jorgensen, W. L.; Ravimohan, C. J. Chem. Phys. 1985, 83, 3050.

(27) Straatsma, T. P.; McCammon, J. A. J. Chem. Phys. 1989, 90, 3300.

(28) Becke, A. D. J. Chem. Phys. 1993, 98, 5648.

(29) Lee, C.; Yang, W.; Parr, R. G. Phys. Rev. B 1988, 37, 785.

(30) Petersson, G. A.; Bennett, A.; Tensfeldt, T. G.; Al-Laham, M. A.; Shirley, W. A.; Mantzaris, J. J. Chem. Phys. 1988, 89, 2193.

(31) Krishnan, R.; Binkley, J. S.; Seeger, R.; Pople, J. A. J. Chem. Phys. 1980, 72, 650 .

(32) Boys, S. F.; Bernardi, F. Mol. Phys. 1970, 19, 553.

(33) Xantheas, S. S. J. Chem. Phys. 1996, 104, 8821.

(34) Frisch, M. J.; Trucks, G. W.; Schlegel, H. B.; Scuseria, G. E.; Robb, M. A.; Cheeseman, J. R.; Zakrzewski, V. G.; Montgomery, J. A., Jr.; Stratmann, R. E.; Burant, J. C.; Dapprich, S.; Millam, J. M.; Daniels, A. D.; Kudin, K. N.; Strain, M. C.; Farkas, O.; Tomasi, J.; Barone, V.; Cossi, M.; Cammi, R.; Mennucci, B.; Pomelli, C.; Adamo, C.; Clifford, S.; Ochterski, J.; Petersson, G. A.; Ayala, P. Y.; Cui, Q.; Morokuma, K.; Malick, D. K.; Rabuck, A. D.; Raghavachari, K.; Foresman, J. B.; Cioslowski, J.; Ortiz, J. V.; Stefanov, B. B.; Liu, G.; Liashenko, A.; Piskorz, P.; Komaromi, I.; Gomperts, R.; Martin, R. L.; Fox, D. J.; Keith, T.; Al-Laham, M. A.; Peng, C. Y.; Nanayakkara, A.; Gonzalez, C.; Challacombe, M.; Gill, P. M. W.; Johnson, B. G.; Chen, W.; Wong, M. W.; Andres, J. L.; Head-Gordon, M.; Replogle, E. S.; Pople, J. A. Gaussian 98, revision A.7; Gaussian, Inc.: Pittsburgh, PA, 1998.

(35) Frenkel, D.; Smit, B. Understanding Molecular Simulation; Academic Press: San Diego, CA, 1996. Allen, M. P.; Tildesley, D. J. Computer Simulation of Liquids; Clarendon: New York, 1987.

(36) Jorgensen, W. L.; Nguyen, T. B. J. Comput. Chem. 1993, 14, 195.

(37) Jorgensen, W. L.; Severance, D. L. J. Am. Chem. Soc. 1990, 112, 4768.

(38) Böhm, H. J.; McDonald, I. R.; Madden, P. A. Mol. Phys. 1983, $49,347$.

(39) Mooney, D. A.; Müller-Plathe, F.; Kremer, K. Chem. Phys. Lett. 1998, 294, 135 .

(40) Singh, U. C.; Kollman, P. A. J. Comput. Chem. 1984, 5, 129.

(41) Besler, B. H.; Merz, K. M., Jr.; Kollman, P. A. J. Comput. Chem. 1990, 11, 431.

(42) McClenman, A. L. Tables of Experimental Dipole Moments; Freeman: San Francisco, CA, 1963; Vol. 1. 
(43) Coutinho, K.; Canuto, S. DICE: A General Monte Carlo Program for Liquid Simulation; University of São Paulo: São Paulo, Brazil, 2000.

(44) Borges dos Santos, R. M.; Lagoa, A. L. C.; Martinho Simões, J. A. J. Chem. Thermodyn. 1999, 31, 1483.

(45) Diogo, H. P.; Minas da Piedade, M. E.; Martinho Simões, J. A.; Teixeira, C. J. Organomet. Chem. 2001, 632, 188 and references therein. (46) Diogo, H. P.; Minas da Piedade, M. E.; Martinho Simões, J. A. Nagano, Y. J. Chem. Thermodyn. 1995, 27, 597.

(47) Kryachko, E. S.; Nguyen, M. T. J. Phys. Chem. A 2002, 106, 4267. (48) Levchuk, V. N.; Sheykhet, I. I.; Simkin, B. Ya. Chem. Phys. Lett. 1991, 185, 339

(49) Lazaridis, T. J. Phys. Chem. B 2000, 104, 4964.

(50) Pedley, J. B. Thermodynamic Data and Structures of Organic Compounds; Thermodynamics Research Center: College Station, TX, 1994; Vol. 1.

(51) Parker, V. D. J. Am. Chem. Soc. 1992, 114, 7458; 1993, 115, 1201.
(52) See, for example: Irikura, K. K., Frurip, D. J., Eds. Computational Thermochemistry. Prediction and Estimation of Molecular Thermodynamics; ACS Symposium Series 677; American Chemical Society: Washington, DC, 1998.

(53) Coutinho, K.; Canuto, S.; Zerner, M. C. J. Chem. Phys. 2000, 112, 9874.

(54) Canuto, S.; Coutinho, K. Int. J. Quantum Chem. 2000, 77, 192.

(55) Coutinho, K.; Canuto, S. J. Chem. Phys. 2000, 113, 9132.

(56) Note, however, that in the case of the differential solvation of phenol and phenoxy in water, the total solvent contribution from $\Delta E_{\mathrm{SX}}$ is nearly $15 \mathrm{kcal} \mathrm{mol}^{-1}$. See ref 23.

(57) Katritzky, A. R.; Zerner, M. C.; Karelson N. M. J. Am. Chem. Soc. 1986, 108, 7213 .

(58) Malaspina, T.; Coutinho, K.; Canuto, S. J. Chem. Phys. 2002, 117, 692 